\title{
Postasphyxial Cerebral Survival in Newborn Sheep after Treatment with Oxygen Free Radical Scavengers and a Calcium Antagonist
}

\author{
K. THIRINGER, A HRBEK, K. KARLSSON, K. G. ROSÉN, AND I. KJELLMER \\ Department of Pediatrics I, Department of Obstetrics and Gynecology and Department of Physiology, \\ Gothenburg University, Goteborg, Sweden
}

\begin{abstract}
Acute, severe intrapartum asphyxia was mimicked by tying the umbilical cord in the exteriorized fetal sheep. After a standard time period cardiopulmonary resuscitation was instituted. In the treatment group ( $n=$ 14) the lambs were given a composition of scavengers of oxygen-derived free radicals and a calcium channel blocker. The control group of lambs $(n=12)$ was given placebo. The trial was blind and randomized. Hemodynamic and neurophysiological variables were measured from 30 min before asphyxia to $2 \mathrm{~h}$ postresuscitation. Mean arterial blood pressure, sagittal sinus venous pressure, heart rate, and cardiac output did not differ between the two groups although dramatic changes took place during asphyxia and resuscitation. Cerebral blood flow measured by 133-Xe washout method increased in both groups immediately after resuscitation. The treated animals retained an augmented cerebral blood flow during the 2 h postresuscitation while the control animals lost the increase of cerebral blood flow. The treated lambs recovered their somatosensory evoked potentials partially or completely in eight of 14 cases while the same figures for the control lambs were one of 12 cases. Immediately after resuscitation the cerebral reactions recovered to some extent in both groups but during the following $2 \mathrm{~h}$ the cerebral cortical function deteriorated in the control group but improved in the treated lambs. It is concluded that part of the brain damage in connection with acute, severe asphyxia may be inflicted by oxygen-derived free radicals released during the reoxygenation phase after resuscitation and that oxygen-derived free radical scavengers and calcium channel blockers may find a place in cardiopulmonary resuscitation. (Pediatr Res 22: 62-66, 1987)
\end{abstract}

\section{Abbreviations}

OFR, oxygen free radicals

HX, hypoxanthine

SEP, somatosensory evoked potentials

HR, heart rate

MAP, mean arterial blood pressure

$\mathrm{CO}$, cardiac output

CBF, cerebral blood flow
The potential hazard of too much oxygen has been recognized for centuries (1) but the mechanisms of oxygen toxicity were first explored during the last few decades (2). During hyperoxia, the OFR (e.g. superoxide ion, hydrogen peroxide, hydroxyl radical, and singlet oxygen) produced from $\mathrm{O}_{2}$, are highly reactive and thereby exert a cytotoxic effect by enzyme oxidation, interaction with DNA, and lipid peroxidation of membranes. Endogenously produced factors for protection against OFR have been developed by the cell. Some antioxidant substances have come into medical use for the prevention of hyperoxic damage. One example of such treatment, although recently disputed, is vitamin $E$ in the premature infant for the prevention of retrolental fibroplasia (3) and bronchopulmonary dysplasia (4). Considering the often limited success in treatment directed against hypoxia in perinatal asphyxia, it is now questioned how much of the injury is actually caused by the liberal provision of oxygen during resuscitation (5).

We have previously studied metabolism during asphyxia in the fetal sheep $(6,7)$ and reported a successive accumulation of $\mathrm{HX}$ in plasma with increasing degrees of hypoxia. During resuscitation the bulk of HX is further oxidized to xanthine and urate, a process liberating large amounts of OFR. In our studies a positive correlation was found between the impairment of cerebral function, as measured by the SEP and the HX output from the fetal brain (6). It is thus conceivable that part of the brain damage following asphyxia is actually inflicted by OFR generated during resuscitation.

In the present study we aimed at the prevention of brain damage after severe, acute asphyxia by treatment with OFR scavengers given simultaneously with conventional resuscitation. The production of OFR is greatly influenced by the intracellular content of $\mathrm{Ca}^{++}$; increasing intracellular $\mathrm{Ca}^{++}$levels catalyzing the generation of xanthinoxidase from xanthindehydrogenase (8) and the accumulation of $\mathrm{Ca}^{++}$intracellularly may lead to a number of adverse reactions resulting in neuronal injury. Thus, the OFR scavengers were given together with a calcium antagonist, the latter to inhibit OFR production. We instrumented exteriorized fetal sheep, tied the umbilical cord while preventing breathing, started resuscitation after a standard period of asphyxia, and recorded hemodynamic and cerebral function variables for $2 \mathrm{~h}$ in the newborn lamb.

\section{MATERIALS AND METHODS}

Material. Twenty-six lamb fetuses/newborn lambs were investigated in a randomized double-blind manner; 14 constituted the treatment group. Gestational ages and birth weights for the lambs in the treatment and the control groups were respectively, $137 \pm$ 8.34 and $140 \pm 4.87$ days and $2827 \pm 629.9$ and $3261 \pm 409.4$ $\mathrm{g}($ mean $\pm \mathrm{SD})$.

Preparation. The pregnant ewes were anesthetized with pen-
Received October 2, 1986; accepted February 11, 1987.

Reprint requests Klara Thiringer, M.D., Department of Pediatrics I, Gothenburg University, East Hospital, S-416 85 Göteborg, Sweden.

Supported from the Swedish Medical Research Council (2591, 5654), MargareResearch 
tothal $(250 \mathrm{mg})$ and chloralose $(35 \mathrm{mg} / \mathrm{kg})$. Anesthesia was maintained with added hourly doses of chloralose.

The fetus was exteriorized and placed on a thermostated table maintaining body temperature at $39^{\circ} \mathrm{C}$. Preparation was performed as described previously (6). In short, catheters were placed in a. brachialis, a. femoralis, a. lingualis with the tip in a. carotis, $v$. jugularis, v. femoralis, and sinus sagittalis. A tracheostomy was performed and the tracheostomy tube was placed under saline until resuscitation. ECG electrodes were placed precordially and on the limbs. EEG electrodes were placed bilaterally over the parietal regions and in the midline over the vertex.

Recordings. MAP was recorded from the right brachial artery and pressure in the sagittal sinus was recorded via Statham pressure transducers model P23AC using a Grass Polygraph 7B.

HR was recorded by an oscillation detector operated by oscillations in blood pressure or in the ECG.

Preductal arterial oxygen tension was continuously recorded by a microtip $\mathrm{PO}_{2}$ electrode (Searle Instrument Ltd., Bucks, England) placed in the end of the catheter in the right brachial artery. The same catheter was also uscd for intermittent blood sampling.

$\mathrm{CO}$ was estimated from indicator dilution curves. Indocyanin green was injected in the inferior vena cava and blood was withdrawn at constant flow rates from the abdominal aorta through a detector cuvette system.

$\mathrm{CBF}$ was measured as described earlier (9) using the 133-Xe washout method after injecting into the carotid artery a bolus of 133-Xe dissolved in saline. A scintillation detector positioned over the head corresponding to the parietal region of the brain recorded the activity changes.

Spontaneous EEG was recorded from the scalp electrodes and the SEP were obtained from a microprocessor unit that averaged 23 or 55 responses to a mechanical stimulus. This consisted of a light tap on the upper lip every other second. The methods for placing the electrodes, the averaging of the potentials, and the scoring of the SEP are previously described (6). The scoring system contains six grades, grade 0 implying a completely normal, undisturbed response and grade 5 signifying a complete loss of electrical activity related to somatosensory stimulation.

Procedure. After a 30-min period of steady state (according to hemodynamic recordings and arterial blood gases) the umbilical cord was clamped and spontaneous respiration was prevented by occluding the tracheostomy tube. The lambs were then subjected to periods of asphyxia with a duration either until asystolic ("severe asphyxia") or to $10 \mathrm{~min}$ ("moderate asphyxia"). Severe asphyxia was instituted in 11 cases, six in the treatment group (mean time to asystole $16.3 \mathrm{~min}$, range $12.5-20 \mathrm{~min}$ ) and five in the control group (mean time to asystole $13.0 \mathrm{~min}$, range 10 20 ). The moderate asphyxia group consisted of 15 cases, eight in the treatment and seven in the control group.

The period of asphyxia was terminated by resuscitation. This consisted of external cardiac massage in cases of asystole, mechanical ventilation of the lungs with a pressure-operated respirator, using $100 \%$ oxygen until the intraarterial $\mathrm{PO}_{2}$ electrode recorded pressures above $10 \mathrm{kPa}$. Then a mixture of oxygen and nitrous oxide was adjusted to maintain arterial $\mathrm{PO}_{2}$ between 10 and $13 \mathrm{kPa}$. During the first $5 \mathrm{~min}$ of resuscitation all animals were given an intravenous infusion of 3 mmoles of tris-buffer in $0.6 \mathrm{M}$ solution. The treatment group of animals was given a slow infusion over the next $10 \mathrm{~min}$ of $15 \mathrm{ml}$ solution consisting of 1methionine $2 \%$, mannitol $5 \%, \mathrm{MgSO}_{4} 450 \mathrm{mg}$ in a $3 \%$ dextrane solution immediately followed by $3 \mathrm{mg}$ of Lidoflazine, 4-4, -bis(4,fluorophenyl) butyl-N-(2,6-dimethyl-phenyl)-1-piperazine acetamide (the drugs given were generously supplied by Pharmacia Ltd, Uppsala, Sweden). The control animals were given equal amounts of $3 \%$ dextrane and saline solutions. The allocation to treatment or control group was performed by one technician by drawing lots from sealed envelopes. Those who performed the resuscitation and the interpretation of the results were not aware to which group the animal belonged.
In some lambs the mean arterial blood pressure did not recover after resuscitation. When mean arterial blood pressure did not exceed $40 \mathrm{~mm} \mathrm{Hg}$ a slow intravenous infusion of dopamine (1$5 \mu \mathrm{g} / \mathrm{kg} / \mathrm{min}$ ) was given. Four lambs in the experimental and four lambs in the control group were given such treatment. Recovery after start of resuscitation was followed until $120 \mathrm{~min}$.

\section{RESULTS}

In the control group 10 of 12 animals were successfully resuscitated and recordings were continued for $120 \mathrm{~min}$ postasphyxia. One lamb did not regain heart activity after severe asphyxia and one lamb in the moderate asphyxia group succumbed at $15 \mathrm{~min}$ of resuscitation. In the treatment group all 14 lambs were successfully resuscitated, but one lamb died $1 \mathrm{~h}$ after start of resuscitation. Thirteen lambs in the treatment group were followed for 120 min postasphyxia.

An example from a typical experiment is illustrated in Figure 1. This lamb was subjected to a severe asphyxia, leading to cardiac arrest in $15 \mathrm{~min}$. The course of the intraarterial oxygen tension, HR, MAP, CO, CBF, and SEP are shown in the lamb belonging to the treatment group.

Figures 2 and 3 present a summary of the hemodynamic events in the two groups. Treatment and control groups are displayed separately. No differences between the groups were observed with regard to MAP, sagittal sinus pressure, HR, or CO.

Initially during asphyxia a marked elevation of the MAP took place, with a concomitant rise in venous cerebral pressure (Fig. 2 ). At the end of the asphyctic period the arterial and the venous blood pressures dropped in parallel. The effect of the procedures for resuscitation was demonstrated by parallel rises in the pressures. During the 2 -h period postresuscitation the sagittal sinus pressure remained at around $8-10 \mathrm{~mm} \mathrm{Hg}$, i.e. the normal preasphyctic level.

The HR fell abruptly during asphyxia and recovered to preasphyctic levels with a transient overshoot as a response to resuscitation (Fig. 3).

FETAL SHEEP $16 / 83,131$ days. COMPLETE ASPHYXIA, 15 min

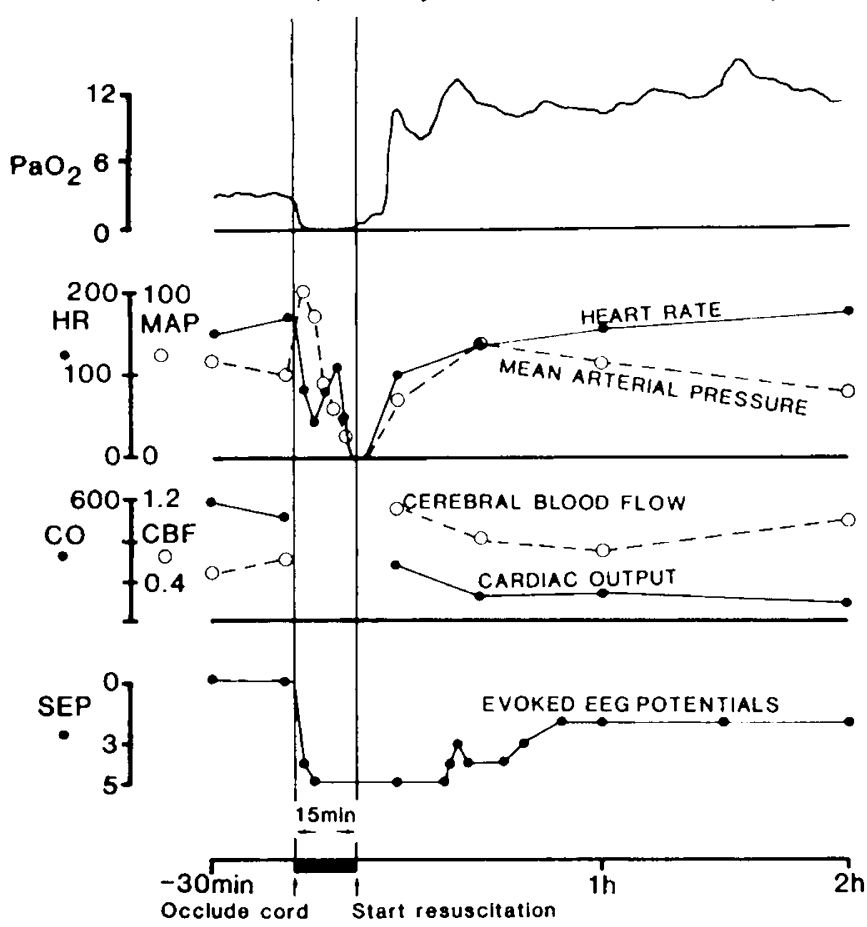

Fig. 1. Example from the treatment group. $\mathrm{PaO}_{2}$ (in $\mathrm{kPa}$ ), $\mathrm{MAP}(\mathrm{mm}$ $\mathrm{Hg}$ ), HR (beats/min), and SEP (arbitrary grades) were recorded continuously. $\mathrm{CO}\left(\mathrm{ml} \cdot \mathrm{min}^{-1} \cdot \mathrm{kg}^{-1}\right)$ and $\mathrm{CBF}\left(\mathrm{ml} \cdot \mathrm{min}^{-1} \cdot \mathrm{g}^{-1}\right)$ were measured intermittently. 


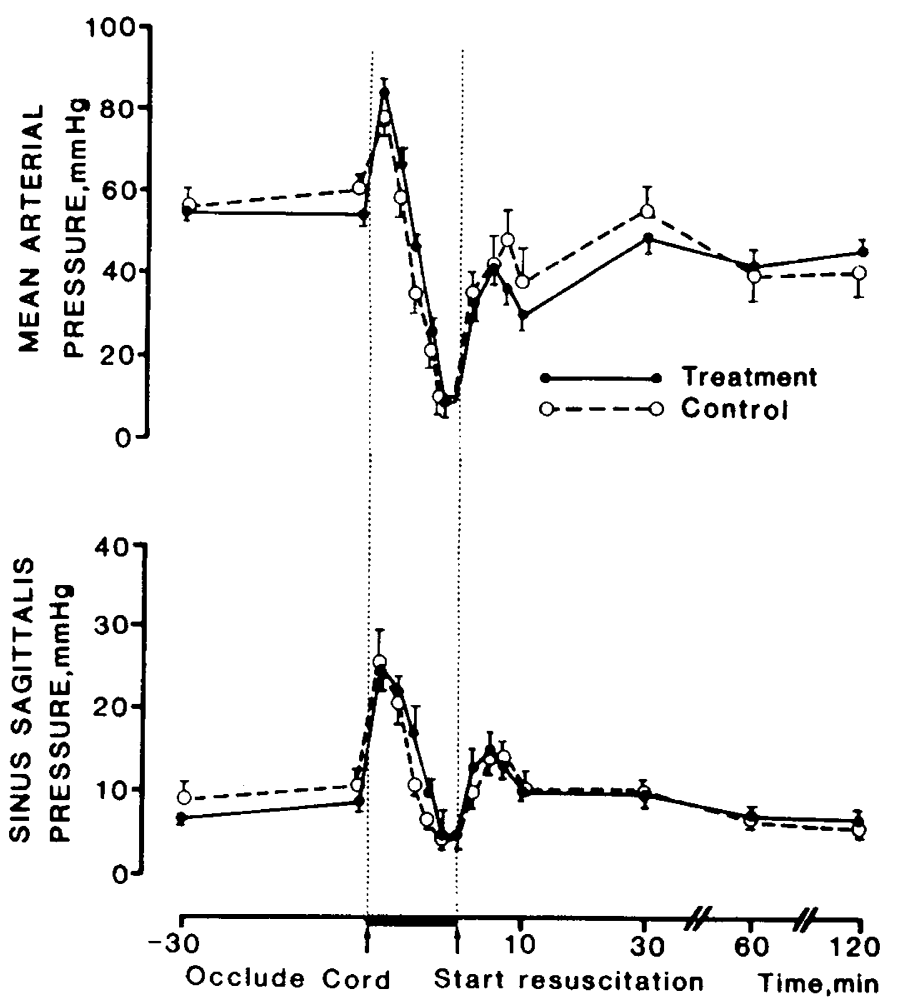

Fig. 2. MAP and sinus sagittalis pressure measured continuously in treatment and control group. Mean \pm SEM are shown.

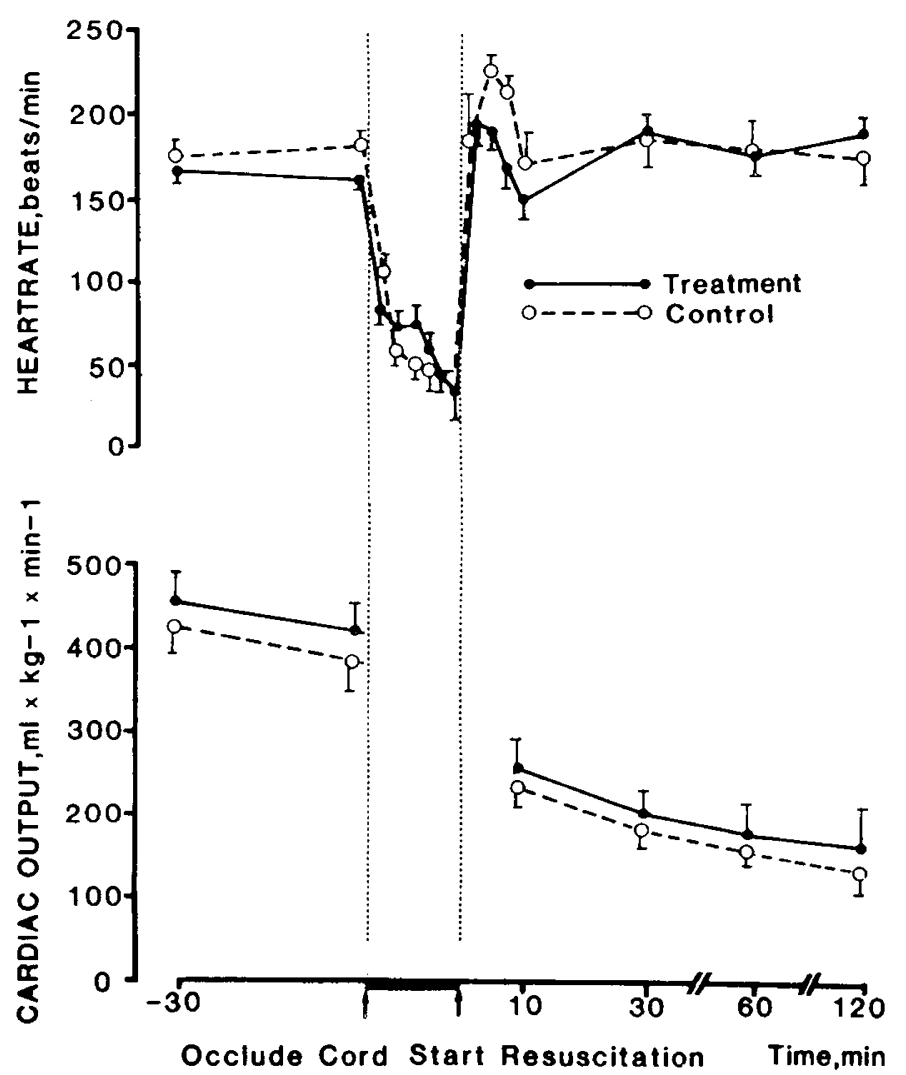

Fig. 3. HR recorded continuously and $\mathrm{CO}$ measured intermittently in treatment and control group. Mean \pm SEM are shown.

The $\mathrm{CO}$ was assessed twice before asphyxia and then at 10 , 30,60 , and $120 \mathrm{~min}$ postresuscitation. The nominal values for $\mathrm{CO}$ after asphyxia were about half of those before asphyxia. It should be observed, however, that before asphyxia the fetal type of circulation prevailed. Thus indicator dilution curves obtained after injection in the inferior caval vein reflect the combined output of the ventricles, while after tying the cord and ventilating the lungs the dye dilution curves reflect the right ventricular output. Therefore, values obtained before and after resuscitation are not comparable.

Values for CBF did not differ between control and treatment groups before asphyxia (Fig. 4). Ten min after start of resuscitation the control animals demonstrated a brisk increase of CBF which subsided so that $\mathrm{CBF}$ values at 60 and $120 \mathrm{~min}$ fell below the preasphyctic level. The treated lambs on the other hand maintained increased $\mathrm{CBF}$ values for the whole post-resuscitation period of $2 \mathrm{~h}$. The CBF values of the treatment group were significantly higher than the control group values at 60 and 120 $\min (p<0.05)$.

The individual courses of the SEP scores in the 26 lambs are shown in Figure 5. All lambs in both groups had normal evoked potentials before asphyxia, i.e. SEP score 0 . During asphyxia the SEP deteriorated rapidly and uniformly. When resuscitation was started the electrical activity from the brain was completely abolished in 11 and 10 lambs in the control and treatment groups, respectively. In the control group one of 12 lambs and in the treatment group four of 14 lambs had some electrical activity left. This difference is not statistically significant $\left(\chi^{2}=\right.$ $1.6, \mathrm{~ns})$. In the control group some improvement of the SEP took place in nine of 12 cases compared to all 14 in the treatment group. The most striking difference between the two groups was that the improvement of the SEP was transient in the control animals (with one exception) while the treated lambs demonstrated a successive improvement of the SEP over the 120-min postasphyxia period.

According to previous work from this laboratory (6) SEP scores of 3,4 , or 5 indicate a very severe deterioration of cerebral function including ATP degradation, while scores of 1 and 2 correspond to slight or moderate alterations of the evoked potentials without signs of intracerebral breakdown of purines. Therefore, we considered SEP scores of $0-2$ as "cerebral survival" and scores 3-5 indicating cerebral damage. The only animal in the

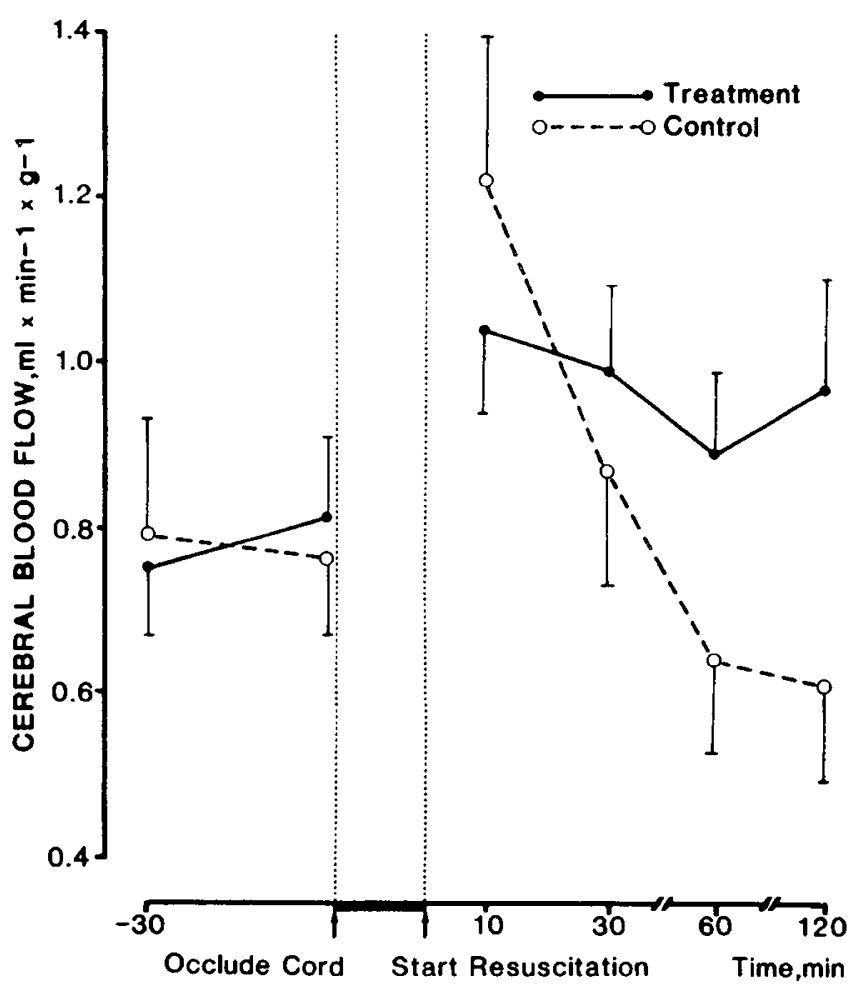

Fig. 4. CBF measured intermittently in treatment and control group. Mean \pm SEM are shown. The differences between the groups at 60 and $120 \mathrm{~min}$ after resuscitation are statistically significant $(p<0.05)$. 


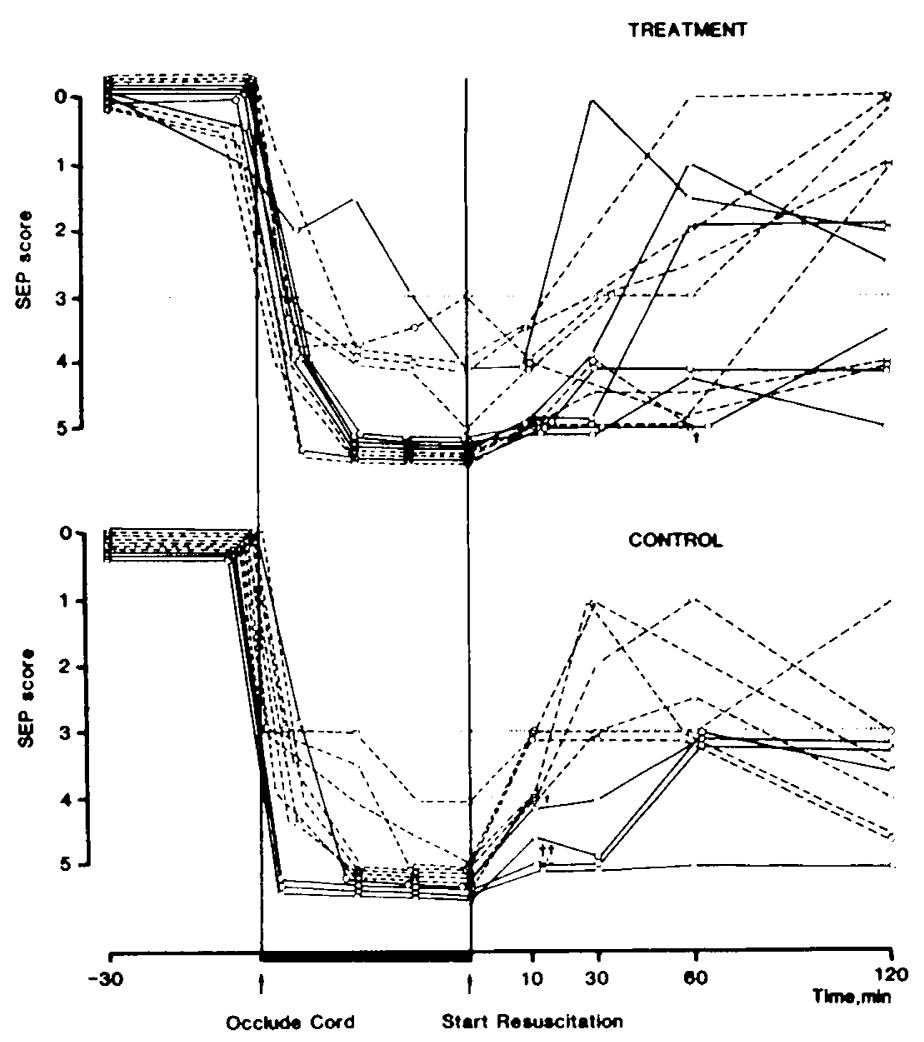

Fig. 5. Somatosensory evoked potentials in treatment and control groups. Each experiment is shown individually. The line at SEP score 3 indicates the definition used for "cerebral survival." Solid lines denote severe and dashed lines denote moderate asphyxia (see text). The crosses show time of death for animals succumbing before $120 \mathrm{~min}$ after resuscitation.

control group that had some remaining electrical activity at the start of resuscitation did not improve to cerebral survival, while three of four lambs in the treatment group with SEP better than 5 , achieved cerebral survival at $2 \mathrm{~h}$.

In contrast to only one in 12 control lambs, eight of 14 treated lambs regained cerebral cortical activity, "cerebral survival." No control animal survived cerebrally from severe asphyxia compared to three of six treated lambs. After moderate asphyxia one of seven in the control group achieved cerebral survival, compared to five of eight in the treated group.

In Figure 6 the course of cerebral survival in relation to time can be seen. Initially, at the start of resuscitation, all animals had SEP scores of 3 or worse. After $10 \mathrm{~min}$ the control group did as well as the treated group. When time for recovery increased the number of animals with cerebral survival decreased in the control group, in contrast to the increasing number in the treated group. At $120 \mathrm{~min}$ after start of resuscitation the difference between the outcome in the two groups was statistically significant $\left(\chi^{2}=5.53\right.$, $p<0.02)$.

\section{DISCUSSION}

Survival rates following severe asphyxia and cardiorespiratory arrest are discouraging. The outlook is especially gloomy when success of resuscitation is defined as meaningful (minimal or no neurologic deficit) long-term survival rather than just reestablishment of vital hemodynamic function (10). Survival rates as low as $5 \%$ for children with cardiorespiratory arrest (11) and between 30 and $50 \%$ for newborns with birth asphyxia requiring intensive care treatment $(12,13)$ have recently been reported. Results from adult series of cardiopulmonary resuscitation are in the same range with $12-16 \%$ unaffected survival, despite high-dose thiopental treatment (14).

These results should be contrasted to findings from experiments which show that CNS neurons can tolerate between 20

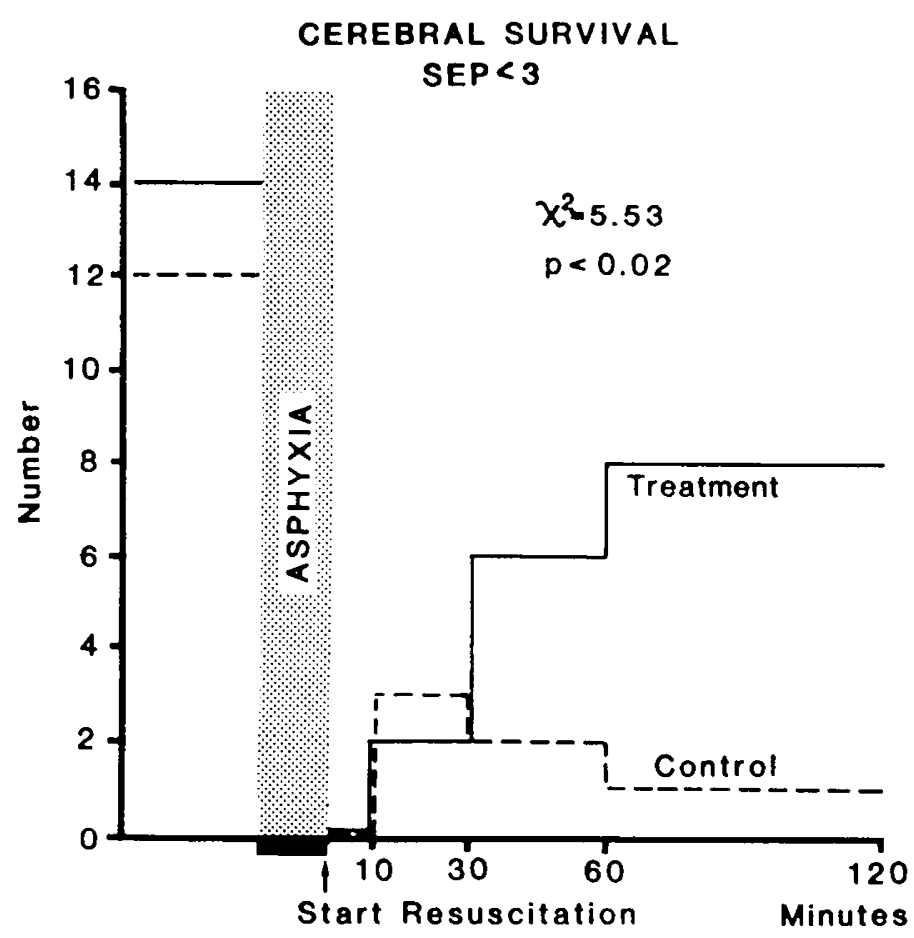

Fig. 6. Cerebral survival in treatment and control group, based on SEP. The difference between the groups at 60 and 120 min after resuscitation is statistically significant $(p<0.02)$.

and $60 \mathrm{~min}$ of complete anoxia without irreversible injury (15. 16). Irreversible damage can neither be linked to complete ATP depletion or to lack of glucose stores (17). Indeed, complete ischemia caused less neuronal death than partial perfusion of the primate brain, possibly due to the lower levels of lactate accumulation (18).

The rationale for the choice of the combination of OFRscavengers (l-methionin, mannitol, and $\mathrm{MgSO}_{4}$ ) is that we wanted to use effective scavengers both against singlet oxygen, superoxide ions, and hydroxyl radicals (19), that are stable in solution and that might be administered to humans. Lidoflazine was used because its documented effect for protection against postasphyctic cerebral damage in adult animals (20).

The figures for short-term cerebral survival after cardiac arrest and moderate asphyxia (50 and 63\%) in the experimental group of the present study should be compared with 0 and $14 \%$ cerebral survival in our animals subjected to conventional cardiopulmonary resuscitation. The difference in cerebral survival between the groups cannot merely be explained on the basis of the hemodynamic results of the study. Both $\mathrm{CO}$ and MAP were equal in the two groups, while CBF differed, inasmuch as the treated lambs maintained a higher perfusion rate after asphyxia than the controls. The ability of calcium antagonists to prevent the cerebral "no reflow" phenomenon after asphyxia is previously described $(21,22)$, and our finding of a significantly higher CBF in treated group is in accordance with it. There were no signs of cerebral hypertension in either group indicative of brain swelling and thus leading to impaired flow. Apparently, mannitol, which was part of the OFR-scavenger treatment did not exert its effect by reducing intracranial pressure. Furthermore, the postasphyxial values for CBF in the control lambs were not significantly below the initial values and also not inferior to values previously found by us in normoxic fetal sheep $(6,9)$. The sustained increase of $\mathrm{CBF}$ in the treatment group is thus ascribed to a vascular effect. It is unlikely that this rather moderate difference in cerebral perfusion rate will be the sole mechanism behind the better short-term cerebral survival in the treatment group. We are inclined to ascribe this additional effect to the administration of the OFR scavengers.

Pentothal was used for induction of anesthesia in both groups. 
Barbiturates have been ascribed an OFR scavenging activity (23). However, this was not confirmed by others (24). Furthermore, a short-acting barbiturate was used only for induction in the present experiments. Therefore it is unlikely that its use could be a confounding variable.

During the time period 10-120 min postasphyxia a gradual improvement of cerebral function was recorded in the treated lambs while, on the other hand, the nontreated control animals only exhibited a transient cerebral recovery and then a successive deterioration.

These findings may be explained by the generation of oxygenfree radicals in the phase of reoxygenation, exerting their harmful effects in the control animals, while the treated lambs were offered some protection by the combination of a battery of OFRscavengers and a calcium ion antagonist.

\section{REFERENCES}

1. Bernard C 1878 Lecons sur les phénomènes de la vie commune aux animaux et aux végétaux. Baillière, Paris

2. Fridovich I 1978 The biology of oxygen radicals. Science 201:875-880

3. Mintz Hittner $\mathrm{H}$, Godio LB, Rudolph AJ, Adams JM, Garcia-Prats JA, Friedman Z, Kautz JA, Monaco WA 1982 Retrolental fibroplasia: efficacy of vitamin $\mathrm{E}$ in a double-blind clinical study of preterm infants. $\mathrm{N}$ Engl J Med 305:1365-1371

4. Coleman M, Thomson TR 1979 A possible role of vitamin $E$ in the prevention or amelioration of bronchopulmonary dysplasia. Pediatr Hematol Oncol $1: 175-180$

5. Fridovich I 1979 Hypoxia and Oxygen Toxicity. In: Fahn S, Davis JN, Rowland LP (eds) Advances in Neurology. Raven Press, New York, pp 255-266

6. Thiringer K, Blomstrand S, Hrbek A, Karlsson K, Kjellmer I 1982 Cerebral arterio-venous difference for hypoxanthine and lactate during graded asphyxia in the fetal lamb. Brain Res 239:107-117

7. Thiringer K, Karlsson K. Rosen KG, Kjellmer I 1984 Contribution of heart muscle, liver, skeletal muscle and placenta to the asphyxial hypoxanthine elevation in the acutely exteriorised fetal lamb. Biol Neonate 45:169-182
8. McCord JM 1985 Oxygen-derived free radicals in postischemic tissue injury. N Engl J Med 312:159-163

9. Kjellmer I, Karlsson K, Olsson T, Rosén KG 1974 Cerebral reactions during intrauterine asphyxia in the sheep. I. Circulation and oxygen consumption in the fetal brain. Pediatr Res 8:50-57

10. Orlowski JP 1984 The effectiveness of pediatric cardiopulmonary resuscitation. Am J Dis Child 138:1097

11. Torphy DE, Minter MG, Thompson BM 1984 Cardiorespiratory arrest and resuscitation of children. Am J Dis Child 138:1099-1102

12. Scott H 1976 Outcome of very severe birth asphyxia. Arch Dis Child 51:712716

13. Nelson KB, Ellenberg JH 1981 Apgar scores as predictors of chronic neurologic disability. Pediatrics 68:36-44

14. Brain Resuscitation Clinical Trial I Study Group 1986 Randomized clinical study of thiopental loading in comatose survivors of cardiac arrest. N Engl J Med 314:397-403

15. Ames AIII, Gurian BS 1963 Effect of glucose deprivation on function of isolated mammalian retina. J Neurophysiol 26:617-634

16. Hossman KA, Cleihues P 1973 Reversibility of ischemic brain damage. Arch Neurol 29:375-384

17. White BC, Wiegenstein JG, Winegar CD 1984 Brain ischemic anoxiamechanisms of Injury. JAMA 251:1586-1590

18. Rehncrona S, Kagström E 1983 Tissue lactic acidosis and brain damage. Am J Emerg Med 1:168-174

19. Halliwell B, Gutteridge JMC 1985 Free Radicals in Biology and Medicine. Clarendon Press, Oxford

20. Vaagenes P, Cantadore R, Safar P, Moossy J, Rao G, Diven W, Alexander H Stezoski W 1984 Amelioration of brain damage by lidoflazine after prolonged ventricular fibrillation cardiac arrest in dogs. Crit Care Med 12:846-855

21. White BC, Gadzinski DS, Hoehner PJ, White JD, Trombley JH 1982 Effect of flunarizine on canine cerebral cortical blood flow and vascular resistance post cardiac arrest. Ann Emerg Med 11:119-126

22. Steen PA, Newburg LA, Milde JH 1983 Nimodipine improves cerebral blood flow and neurologic recovery after complete cerebral ischemia in the dog. $J$ Cereb Blood Flow Metab 3:38-42

23. Flamm ES, Demopoulos HB, Seligman ML, Ransohoff J 1977 Possible molecular mechanisms of barbiturate-mediated protection in regional cerebral ischemia. Acta Neurol Scand 64:150-151

24. Smith DS, Rehncrona S, Siesjö BK 1980 Barbiturates as protective agents in brain ischemia and as free radical scavengers in vitro. Acta Physiol Scand [Suppl] 492:129-134 